add, may also result from original malformations of them. Thus, for instance, there may be one valve only at the aortic orifice, or two of the valves may adhere together, or the three may be present, and one of them very small and in a rudimen. tary state. Congenital defects of the valves of the pulmonary artery are generally associated with other serious organic defects of the heart or its vessels, such as are incompatible with prolonged life. They are therefore rarely met with, except in the very young.

\section{REMARKS ON DR. SKINNER'S CASE OF SUSPECTED POISONING BY OXALIC ACID.}

By J. L. W. Thudichum, M.D.

The last number of the Britrsh Medical Journal contains an account of a case of suspected poisoning by oxalic acid or its salts, by Dr. Skinner of Liverpool, upon which $I$ beg to offer a few remarks.

An unmarried female was on the Sth of November seized with a severe rigor, followed by an attack of acute peritonitis. Twelve leeches were applied to the abdomen; and the ordinary ice and opium treatment was adopted. Seven days after, the patient was convalescent. On November 20 th, a relapse occurred. T'he peritonitis, which before was general, was now limited to a small spot in the left umbilical region. There was occasional vomiting and retching, etc.; consequently the tongue was furred, and the thirst intense. Eight leeches were applied over the painful spot, followed by large anodyne poultices, and ice and opium. In two days, the patient was again convalescent. On December 1st, the patient complained of continued nausea, drank warm water, and accordingly vomited; but the nausea continued. On December 2 nd, she had been vomiting more or less during a space of twenty-four hours, and was apparently rapidly passing into collapse. Creasote and morphia were given; mustard poultices were placed on the hypogastrium ; and the patient surrounded with bottles of hot water. Later, hydrocyanic acid was given in effervescence, with bicarbonate of potash and lemon-juice. Beef-tea and port wine were administered per anum. In the evening, vomiting had entirely ceased, and reaction was fairly established. Next day she had "twitchings", during the occurl'ence of which a copious flow of dark coloured fluid passed from the patient per vaginam. So copious was it, that it saturated the napkin and the bedclothes. In a day or two from the date of the excessive vomiting, the patient was thoroughly convalescent. Six ounces of the fluid vomited by the patient on December 2nd were examined, and found to contain no poison. The patient, who is described as healthy, had on a previous occasion six leeches applied to her, on account of inflammation of the cervix uteri.

This is the essence of the case, divested of its atmosphere of suspicion.

Giving Dr. Skinner full credit for the correctness of his diagnosis, so far as regards the existence of peritonitis, this would probably be the first case on record in which the cause of such a clear acute attack of peritonitis is ever alleged to have been an irritant poison. But, even admitting that such symp. toms as those observed during the second and third attacks might be produced by oxalic acid, there remains one symptom which cannot be explained by the assumption of poisoning simply ; namely, the bloody discharge at the crisis of the dis. order, two days subsequently to which the patient was thoroughly convalescent. Dr. Skinner is not able to account for this discharge of blood, which produced stains resisting all domestic efforts at removal.

This blood was evidently not ordinary blood, coming direct from an artery or vein, or from capillary vessels; for such blood does not produce stains resisting the domestic efforts at removal. For the same reason, it cannot be considered as fresh menstrual blood, particularly if we give credit to the statement that the catamenia had appeared shortly before her illness. But if we consider this blood to have been effused into some internal cavity some time before its discharge, and there to have been retained and altered, then the colour of the fluid, the copiousness of its flow, and the peculiar nature of the stains, are satisfactorily accounted for.

Now, as peritonitis preceded by rigors, being itself a very rare disorder, is not produced by oxalic acid taken into the stomach, and as a sudden discharge of blood from the vagina, or perhaps the discharge of an accumulation of blood from the uterine cavity, or the accumulation of blood in the uterine cavity, are not symptoms or sequels of oxalic acid introduced into the system, we have here the two most important elements in the disorder, the beginning and the critical end, which absolutely deny the possibility of poisoning by oxalic acid.

On the contrary, if we assume the large quantity of peculiar blood to have existed in the uterine cavity at the beginning of the disorder, on November 8th (which, in a female who had before been suffering from inflammation of the cervix uteri, so that six leeches had to be applied to the os uteri by Dr. Skinner himself, is an assumption supported by great probability), then all the symptoms of peritonitis, general and local, the romiting, the nauser, the twitches, and the discharge, the amenability of the case to treatment, the very rapid and complete recovery, are satisfactorily accounted for.

No poison was found in six ounces of matter which had been vomited by the patient. During the night preceding this particular act of vomiting, oatmeal gruel had been administered every half hour or so, but always came up instantaneously. Now this very oatmeal gruel, being the suspected vehicle, should reasonably have had a peculiar acid taste, had it contained oxalic acid-a taste which the patient must have noticed, and which she could not merely describe as a taite different from that of tea and other liquids of which she partook about the same time. The taste of oatmeal gruel is distinctly different from the taste of tea and other liquids, even when that gruel is quite pure and unadulterated with oxalic acid. The avidity. with which the patient says she swallowed the gruel, is an afterthought, and evidently invented to account for the real absence of any peculiar taste of the gruel. Some of this gruel, given every half hour, must have been in the stomach at the time the vomiting occurred, the produce of which was analysed, and found to contain partially digested starch-granules, but no oxalic acid. It was an afterthought of the patient, of which she informed Dr. Skinner, that she had similar gruel before this illness, which never did more than nauseate, and that she suffered from " everlasting nausea", "now and again", for the last two years. The patient evidently neither remarked nor said anything about her gruel, either during the last two years or this present illness: it was all elicited from her by the sug. gestion of poisoning, and then nothing was elicited supporting in any way that suggestion.

The following statement is adduced in support of the case having been one of poisoning by oxalic acid:- "I have been told since, that they" (the twelve and eight leeches applied on two occasions) " did not fix well, that they soon came off, and, with one exception, they all died immediately, the only exception dying next day." But the leeches which the author himself had formerly applied to the os uteri had all lived long after that service. A case by Dr. Arrowsmith, reported by Christison, has evidently suggested the inquiry about the leeches.

Had the information about the leeches been obtained immediately after the event, it could perhaps have been credited. But, regarding this piece of information, all control is wanting. It is not even said who informed Dr. Skinner of the dying of the leeches; it is not said who administered the leeches, who took them off, and how they were treated. A leech kept in the dry over night, in a warm room, particularly if it has been roughly handled, is almost sure to die. Leeches frequently fix badly, or soon come off, even when they have been sucking quite healthy blood. Leeches also have been observed to die after use upon patients who certainly did not suffer from poisoning by irritant poison. Further, in the case of Arrowsmith, the proof is yet wanting that those leeches which died, died in consequence of the admixture of oxalic acid with the blood, or in consequence of any change in the blood produced by oxalic acid. This whole statement about the leeches is, in our present case, a baseless fabric of vision.

In a medical point of view, then, the case offers no peculiarity whatsoever. It was a case of chronic disease of the uterus, either chronic inflammation of the cervix, or its consequences, narrowing or obliteration of the cervical canal; or, what is also very likely, and accounts better for the alleged regularity of the catamenia, it may have been a case of antero- or retroflexion of the uterus, diseases which are not rarely accompanied by inflammation of the cervix uteri. As is very common in such cases, catamenial blood was retained in the cavity of the uterus, and altered in the usual manner. This condition, then, produced the very common symptoms connected with the nervous system, recurring or intermittent attacks of pain in the abdomen, which pain was treated as peritonitis, but is perhaps more properly described as uterine colic, with irradiation of the hyperæsthesia over some or all of the 
nervous plexuses of the abdomen. As is usual in such cases, the symptoms increased in severity with every new attack, the cause persisting. The hard and wiry pulse, the furred tongue, the intense thirst, the occasional vomiting and retching, the perspirations covering the forehead, the aspect of the patient, expressive of extreme agony, which the drawn-up knees indicate to be localised in the abdomen-all these are symptoms characterising obstruction of the cervical canal of the uterus, and collection of fluid in its cavity. If during these attacks of pain the uterus had been examined attentively, I have no manner of doubt but that a series of contractions and relaxations of its tissue would have been observed.

Vomiting, which during the second attack had been moderate, became the prominent symptom during the third. Nothing is more common in such severe cases of uterine disease than nausea, occasional sickness, or continued vomiting during severe attacks. In many such patients, general perspirations, seizures of trembling, faintness, or real fainting, follow the sickness and vomiting. The pains pass from the abdomen into the thighs. Tenesmus of rectum and bladder are frequently superadded, producing a desperate condition of the patient, causing sometimes loud lamentations; when continued, this state passes into a chronic disorder of the nervous centres, which, under the name of hysteria, produces a great variety of outbreaks of a very severe nature.

But the symptoms in the third exacerbation of the case under consideration were not of so severe a nature. The patient, when seen on Dec. $2 \mathrm{nd}$, at 7 A.x., had been, or was stated or said herself to have been, vomiting for upwards of twenty hours. At the beginning of these twenty hours, that is, on Dec. 1st, in the morning, the patient had, with the consent of her medical adviser, taken some warm water, to relieve a feeling of nausea. Upon this emetic, the patient had vomited; but the nausea persisted. Gruel of oatmeal was then administered to her every half hour or so ; but it always came up instantaneously, even before she had time to lay down the bowl. The story of the avidity with which she drank this gruel I have already disposed of. But, eveu granting it, it would imply that she every time took a large quantity, to be immediately vomited again; and this she did to quench a thirst, which was much increased by each dose of the gruel, instead of quenched.

What other issue of this sequence of events could be ex. pected by any rational physician than what followed? Cold extremities ; forehead and cheeks moist and clammy ; respiration impeded; tongue thickly furred like wash-leather, red round the edges; eyes lustreless ; cheeks fallen in, countenance anxious, and general expression "cadaverous"; uncontrollalle thirst, which had to be gratified, despite the urgency of the retching, vomiting, and hiccup (with other liquids, probably, as the gruel had been discontinued many hours before Dr. Skinner's arrival). She suffered most from a severe burning pain internally, increased on pressure at the scrobiculus cordis, which was tender when touched.

I will not criticise the emetic of warm water; it might have been useful or hurtful. Any person, however, who has ever vomited, or observed vomiting in others, must have noticed that, after vomiting from any cause, the stomach requires to be kept empty for several hours, in order to return to its state of quietness, and tolerate the presence of food. In cases where the vomiting is preceded by long continued nausea, this condition is particularly essential. A woman, or a man, who eats half an hour after a vomiting from what is called sick headache, is almost certain to vomit again, and will continue to vomit as often as the stomach is irritated by the introduction of any article of food or drink, of water, or even of the swallowed saliva; it does not require the introduction of any poison to produce or keep up this condition.

There is no doubt that the patient, after the emetic of warm water, continuing to be nauseated, kept up the irritation of the stomach by half hourly doses of oatmeal gruel and other liquids, thereby foolishly believing herself to be able to quench a thirst, which she had not advice, or intelligence, or self.control enough to suffer for a time as an indispensable condition to the recovery of her stomach. The suggestion of the administration of poison is not wanted to explain the symptoms, but is, on the contrary, quite superfluous.

A little soda-water (carbonic acid is an anæsthetic and special stimulant) and warmth acted so kindly upon the patient, that she was better when again seen by Dr. Skinner and Mr. Marsh. Hydrocyanic acid and ice soon quieted the stomach; beef-tea and port wine per anum restored her strength and spirits, which must have been sadly tried by the fatal prognosis, and the legal and clerical visits.
Should anybody think it likely that symptoms produced by oxalic acid, taken in doses sufficient to cause a twenty hours vomiting and retching, could pass off so rapidly as the symptoms in this case, that person's mind will be disabused by the account of the day following the night, on the morning of which she was believed to be dying. Some hours after the vomiting had ceased (so the nurse and the patient stated), in voluntary twitchings between the shoulders and back of the neck occurred, which drew the head backwards, and the shoulders against each other. The flexors of the upper and lower extremities showed the same involuntary twitchings, which were frequent, but short in duration, and more annoying than painful. They lasted for twenty-four hours; and now comes the denouement. During the occurrence of these symp toms, a copious flow of dark coloured fluid passed from the patient per vaginam. So copious was it, that it saturated the napkin and the bedclothes.

Reading the facts chronologically and rationally, we must say :-A few hours after the cessation of the vomiting and retching, a copious flow of altered blood from the cavity of the uterus took place, during the occurrence of which, which lasted for more than twenty-four hours, the patient had twitches, or rather fidgets. The vomiting and retching had no doubt a great share in propelling the blood through the nar. rowed or obstructed cervical canal; and, allowing that the discharge may for a few hours have passed unnoticed, it is not straining the evilence to say that the severe symptoms ceased about the time when the discharge began. This sudden discharge of altered blood from an obstructed uterus, after severe symptoms, with immediate and lasting relief, has repeatedly been observed as an element of natural disease, but never as a complication of poisoning by oxalic acid. The twitches are frequent accompaniments of such and other uterine discharges; they often follow spasmodic action of a severer nature, as the sheet lightning succeeds the thunder-storm. They are as different from the painful cramps produced by oxalic acid, as from the spasms of epilepsy or strychnism.

The inedical part of the story, therefore, affords no case to go to the jury. It is a clear case of natural disease, every element of which disproves the very thought of poisoning. I will now examine the accusation which Dr. Skinner brings against the domestic attendant of his patient, and will first recapitulate the circumstances of the alleged intended victim; next of the servant, who is accused; then the facts upon which the accusation is based; and, lastly, consider the imputed nature of the imputed crime.

C. W., unmarried, a young, healthy, and intelligent, but unsuspecting female, an orphan, without relations of any kind, friendless, and having no one to inherit her means, which consisted of household furniture, bed and table linen, and bijouterie, to the value of about $\mathfrak{E} 100$. Her means of living are comparatively moderate. She occupies a house for herself, and keeps a female servant. In December 1857, she suffered from inflammation of the cervix uteri ; since that time, she has frequently suffered from nausea. The servant was bired about the end of $185 \%$. She is much older than her mistress, and has obtained the upper hand of her. Her appearance is most unprepossessing, and her previous character was bad. She knew the circumstances of her mistress. Up to the time of the last attack of her mistress, there was evidently no complaint against her. But, on the 1st of December, Ir. Skinmer began to have " misgivings" about her, and accordingly watched her conduct. On the morning of December 2 nd, shortly after 6 o'clock, A.M., she called him to her mistress, who (she is reported to have said) was very ill with vomiting, and just at the point of death. Dr. Skinner arrived at 7 , and found the servant cleaning the windows and humming to herself. She opened the door, and told him that her mistress was " bilious"; that she was often complaining that way; that she (the servant) was tired of her place, as her mistress was no sooner well of one thing than she was ill of another, and she was not able to sit up all night and work all day.

If it is considered that the mistress herself, on the previous day, had informed Dr. Skinner that she thought her nausea to arise from the presence of bile in the stomach; and that the patient, according to her own statement, had for two years of ten suffered from nausea,-the statement of the servant appears essentially true. There is no evidence of criminal intention in anything she said. It is simply what an old, cross, dissatisfied female, having no particular affection for her mistress, might be expected to say after a sleepless night of waiting upon a vomiting person. But she was already suspected, and the person who heard and reports her speech and behaviour is the

. 
suspecting party; and for that relation we must make some allowance, as regards the coloration of the events.

The next portion of the suspected conduct of the servant is that under No. 3 of the Remarks. On various occasions during her illness, but more particularly on the day of vomiting arid collapse, the domestic said to her mistress that "she was quite astonished she had not made some arrangement about her affairs, as she could not have long to live". This is one of the data on which the suspicion of poisoning rests; yet, on the same day, Dr. Skinner and Mr. Marsh, having so little hope of her recovery, suggested to her to receive a visit from a clergyman and a lawyer.

The judgment and good-will of the servant and the medical attendants seem to have been at par in this matter, at least. But what the doctor considers as right when done by himself becomes evidence of criminal intentions when done by a servan who had served her mistress for two years without having given dissatisfaction. Was there anything more natural than that this servant should have had a legacy bequeathed to her by her mistress, who had no one to inherit her means? Could any person make a suggestion less selfish and more clums than the remarks which the servant made to her mistress? Can it be believed for a moment that this clumsy person should conceive so intricate a crime as that suggested, and hope to obtain the property of the mistress by the last will of the victim of her poison?

But the data on which the suspicion of poisoning rests did partly not transpire until a day or two after the violent vomiting and collapse. Perhaps the above suggestion of suspicion is one of those late fruits of early thought; perhaps it is also an after-thought.

Under 4, 5, and 6, are enumerated various alleged acts of neglect or disobedience on the part of the servant, by which it is sought to prove her guilty intentions. The domestic allowed the patient to vomit for nearly twenty hours, and called Dr. Slinner only at the repeated request of her mistress. The mistress was bilious; she had been often so ; and the servant, during the hours of the night, probably saw no reason for alarm. People also dislike to call the doctor during the night, in December; or to leave a vomiting person, where there is nobody else in attendance. It is more probable still that the servant had no right to call the doctor upon her own responsibility, and that the patient put off giving the order for calling him as long as possible, in order to avoid the increased charct of attendance at night. When she at last gave the order, she probably repeated it impatiently within a short time. 'The charge of neglect and disobedience is evidently invented after the mistress had been nursed with suspicion, and suspicion had effectually been fastened upon the domestic. Surely no charge of criminal intent can be based upon evidence coming so late from so prejudiced a person as the unsuspecting female must have been after she had learned the apprehensions of Dr. Skinner.

Under 5, Dr. Skinner illustrates the efficacy of his precau tions. It will be remembered that on December 1st, "before leaving the patient's house, he began to have misgivings" about the domestic; and, as he could not account for the nausea., so he ordered her (the domestic) to keep anything which might come from her mistress for his inspection. He expected the servant to convict herself; and would no doubt have furnished another illustration to the Esopian fable of the buck who was appointed gardener, had any act of poisoning really been com mitted. A moment's consideration will show that the servan could not think the matters vomited by her mistress to be worth keeping. As the person having the upper hand, this small act of discretion of her who had the sole attendance on her hands will easily be allowed. What was vomited consisted of the drinks swallowed the moment before, mixed, probably with a little saliva and gastric juice. Fifty out of a hundred persons would not have believed themselves to act in accordance with the sense of the instructions of the doctor by keeping these returned drinks of oatmeal, gruel, and other liquids. Besides, it is a question whether the instruction of the doctor, as given above by himself, comprised vomited matters; and whether the servant did not confine her attentions to alvine excretions, both fluid and solid; and by the tenor of the order and the ordinary use of the language, was not quite right in so confining herself. But, granting it to be wrong, and altogether unexplainable by good natured assumptions-forgetfulness, for example, which the physician so often meets with regarding the self-same instruction in the most straightforward casesthen what can be laid to the door of the servant is neglect and disobedience to the doctor-contempt-anything - but certainly not an intention to conceal a crime. For a crime has yet to be proved; and it is absurd to adduce a circumstance as a proof of concealment of a crime before a crime has been proved to have been committed. Somebody must have been murdered before anybody else can be a murderer.

The next and last suspected act of the servant is that, in. stead of rice-porridge, ordered by Dr. Skinner, she gave her mistress oatmeal-gruel. This is one of the data on which the suspicion of poisoning rests. There might be some sense in this disobedience, if oatmeal-gruel presented any peculiar facility for administering oxalic acid to other people, if it covered the acid taste of this poison; but, in absence of such peculiar qualifications, we have to search nearer for the reasons of this choice. Here it is. The patient had often been given, by the same party, a somewhat similar gruel before this last illness, which did never more than nauseate. The oatmeal was in the house; the rice had probably to be fetched; the gruel had often been taken before; there was a feeling or prejudice in its favour, or it was taken for the sake of convenience. Rice-porridge would take an hour's careful boiling, oatmeal gruel a quarter of an hour, leaving aside the question whether thin gruel was not more acceptable to a sick person than thick porridge. This unsuspecting female ate or drank a somewhat similar gruel often during two years, and it is not suggested that she on those frequent occasions devoured it with avidity. She deliberately and slowly put into her mouth and swallowed a gruel, after which she felt nauseated, and which, it is now suggested, was drugged with oxalic acid.

This insinuation is so contrary to common sense, and is so evidently an ex post facto invention, elicited from the patient by what is technically called a leading examination, that $I$ stand aghast at this defeat of reason by suspicion-nay, by superstition-by one of those unaccountable events which lay hold of the human intellect, and stop or pervert its action. I fully believe Dr. Skinner and Mr. Marsh to be most honourable men, men of integrity and principle; but in this sad case the constellation of public feeling regarding poisoning cases, and of their own exaggerated apprehensions derived from an imperfect study of the literature of late poisoning cases, has led them into a grievous error, by which they missed the true interpretation of a case of natural disease, and, with the best will to protect a supposed victim, they wrongly accused and sacriticed another, who, without means of defence, without even having heard the accusation against herself, is considered as convicted, and punished by a summary discharge. These suspicions will become known; and I question whether it will be possible for this discharged servant to obtain or retain any new employment in her former or any other domestic capacity. For what I know of life, this person will be ruined for the rest of hers; and I should not wonder if, in later years, she should be known among people at Liverpool as an object of execration, pity, or fear.

The accusation against this unfortunate woman may be summed up as follows :-She stands accused; and Dr. Skinner publicly and deliberately accuses her, both in the Liverpool Medical Society and in this Jounnar, of having on various frequent occasions during the period of two years ending December 1859 administered to C. W. small but increasing doses of a deadly poison called oxalic acid, with intent to do her grievous bodily harm; and of having, on or about December 1st, 1859, administered to the same C. W. such a quantity of said poison as was likely to be suddenly fatal, with the felonious intention of taking away the life of the said C. W. The suggested motive is the suggested desire of the accused to put herself in possession of the property of her mistress, or of a part thereof, be it by persuading her to make a will in her favour, or by other means.

This enormous accusation, uttered publicly and discussed in private, Dr. Skinner considers as proved. He believes his case to be interesting, "because the crime was detected in time to save the victim". Dr. Skinner was bound in law and duty to bring the charge before the tribunals of this country, there to be substantiated or refuted. Above all things, it was his duty to inform the person herself of the accusations against her, whose character he now is executing in public without the knowledge of that person. Dr. Skinner has, in my opinion, laid himself open to the charge of hastiness, at least. If Dr. Skinner can bring himself to see his error, he should quickly and openly withdraw the fearful charge which he has made against a person who, upon the present evidence, is innocent.

With the issue, which all right-minded persons must unite in desiring, I should not regret the occurrence of this case, as it would teach a wholesome lesson to some over-sensitive 
members of the profession, who, seduced by the cries of scribblers in our public journals living upon the manufacture of baseless apprehensions, and by the small talk of poisonmongers and the effrontery of incapable analysts, see poison at the bottom of every complicated case of disease which resists their remedies or baffles their attempts at diagnosis. It would $t \in$ ach a lesson, which has been taught in two late notable cases, with increased force; namely, that where poisoning may reasonably be suspected, intrinsic evideuce of the existence of poison must be indubitably present, before circumstantial evidence can be allowed to direct suspicion or accusation against any person whatsoever. It would also assist in making the proof of poisoning more dependent upon the finding of the poison either in the body of the victim or in matter derived from him, or in the possession of the supposed poisoner. In this respect, it might restore a morale which has been destroyed by the persuasion of blunderers, who shielded their shortcomings by a novel creed, which in its climax amounted to the absurdity that the proof of poisoning consists in the absence of the poison. Let it be written in large letters into every book on poisons, into every mind, that the absence of poison, in cases where it is suspected to be an agency and is deliberately searched for, amounts to a strong proof in favour of the assumption that no such agency was at work.

I cannot conclude without stating that, although the Liverpool case has caused me great commotion of mind, yet $I$ have no desire to be otherwise than courteous and polite to the gentleman who represents it. I wish expressly to disclaim the weakness of animosity, or the desire of controversy with a medical colleague. A strong sense of duty was the propelling power under which I penned this article. I well know the feeling of the profession of this country, as well as the public mind upon the question of secret poisoning. I well know the same feeling of the same classes in three other countries, the most important of the civilised world. Medical men and laymen are everywhere rife with suspicions of poisoning. Two Prussian chemists find conia in a person suspected to have died of poison feloniously administered. The analysts of the government at Berlin find this alleged conia to be a little carbonate of soda. Four chemists, at Vienna, analyse the organs of a person alleged to have died of irritant poison. Two of the chemists find arsenic, but no antimony; the two other chemists find antimony, but no arsenic. 'These are fitting pendants to the analyses in the Richmond case and the Whitechapel case. Such analyses are more dangerous to the public than the most intricate and clever poisoning, because they tend to destroy innocent people, as well as to insure safety to the real poisoner. Society thus becomes a loser in a twofold sense.

I would not like to be thought harsh in my opinion upon any errors which have occurred and will occur-I hope at a decreasing ratio-in the practice of every aspiring man, keepin mind the Hippocratic aphorism, according to which, experience is treacherous and judgment difficult. We should judge every man not only from his deeds but from his animus as well. I wish it to be understood that I believe all the above analyses to have been made with the most honest wish for justice the security of inaividuals, or, as they are philanthropically called, "society ;" but they were not, what a chemical analysi always is, a mathematical proceeding, but a sort of pseudochemistry, which, instead of protecting, damaged society, and ruined its practitioners.

Medicine in Australia. The medical profession in these colonies comprises every variety of the genus doctor. Without stint or limitation, all comers have been at liberty to embark in enterprises of Esculapian art. Without let or hindrance, all manner of ingenious gentlemen have shaken themselves into the fraternity, and are now reckoned as of the faculty. The exigencies of the community fell too suddenly and urgently upon it to permit a very nice discrimination; and, the moment of distress, when the doctor's services were in requisition, was not the time to investigate his character and pretensions. A doctor was a doctor, whether he had qualified at the university or dubbed himself impromptu for the occasion... . . His services were in demand, and they were usually handsomely, often profusely rewarded; and whether their performance was beneficial or detrimental to the invalid, was seldom in the reckoning. If the former, it added nothing to reputation; if the latter, it had no effect as a salutary warning to others. (From an article on Medical Reform, in the Australian Medical Journal, October 1859).

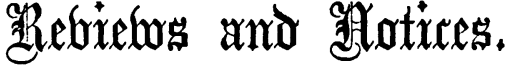

The Anatosiy of the Huran Lung; an Essay, for which was awarded the Fothergillian Gold Medal of the Medical Society of London. By A.T.Hovghton Waters, Member of the Royal College of Physicians of London; Lecturer on Anatomy, Physiology, and Pathology, in the Liverpool Royal Infirmary School of Medicine. Pp. 231. London: John Churchill. Liverpool: Adam Holden. 1860.

THIs work consists of two parts : the first of which is a Historical Sketch, while the second contains the proper subject matter of the essay.

In the historical sketch, Dr. Waters gives an account of the doctrines entertained regarding the structure of the lung by the principal authors who have written on the subject from Hippocrates down to Milne-Edwards. Whenever practicable, he has quoted the words of the authors whom he has consulted; and has thus furnished a very interesting epitome of the literature of the subject.

In the second part, which naturally forms the greater part of the essay, the author describes the structures in the following order: the Pleuræ, Trachea, Bronchi, Substance of the Lungs, Bronchial Tubes, Ultimate Pulmonary Tissue, Bloodvessels, Lymphatics, Nerves, Fuetal Lungs, and Development of the Lungs. The descriptions given are derived from the author's own dissections, compared with the accounts given by previous writers; and the whole bears evidence of great care and industry. He has made special examination with regard to the structure and arrangement of the ultimate pulmonary tissue and the blood-vessels; and we will give an account of his views on these subjects.

A bronchial tube, he says, having entered its lobule, divides and gives off branches, and at last terminates in a dilatation which has opening into it a number of orifices. These orifices lead to canals, which have received various names: such as "intralobular bronchial ramifications" (W. Addison); "lobular passages" (Todd); " intercellular passages" (Rainey); "infundibulums" (Rossignol); "Malpighian vesicles" (Moleschott) "terminal cavities" (Mandl). To these terms, Dr. Waters finds more or less objection; and proposes to use the designa. tion air-sacs for the canals in question.

"The air-sacs are those tubes in which the bronchial ramifications end; they are situated at the surface, and thoughout all parts of the lung; they are supported externally by the pleura, and within the lung they in part rest by their extremities, or their sides, against the bronchial tubes, and the branches of the blood-vessels, and through the transparent coats of the smaller bronchial tubes they are visible, as through the pleurs.

"The air-sacs consist of somewhat elongated cavities, which communicate with a bronchial ramification by a circular opening, which is usually smaller than the cavity to which it leads, and has sometimes the appearance of a circular hole in a diaphragm, or as if it had been punched out of a membrane which had closed the entrance to the sac; when this is the case, the sac dilates suddenly beyond the orifice.

"The sacs are arranged in groups ; they are placed side by side, and are separated from each other by thin membranous walls; their shape, when properly inflated, or when distended by some material which has set in the sacs, such as gelatine, or a mixture of wax and turpentine, is polygonal; they approach very nearly to the circular form, but, in consequence of their mutual pressure, their parietes become somewhat flattened. The sacs increase somewhat in size as they pass from the bronchial tube to their fundus, the latter being usually the broadest part of the sac; but they are often found to have an almost uniform diameter throughout.

"All the sacs pass from the extremity of the bronchial tube towards the circumference of the lobule in which they are placed; they consequently radiate from the tip of each terminal bronchial twig. The sacs connected with one bronchial termination do not communicate with those of another; each set of air-sacs is therefore a little lobule, or lobulette, which, in 